\title{
Risk of Developing Complications among Contact Lens Wearers in Northern Border Region, Saudi Arabia. A Retrospective Cohort Study
}

\author{
Heba Hamed Salem ${ }^{1 *}$, Inaam Shahed Alshmary², Bashair Owed Alharby ${ }^{2}$ \\ and Iman Saury Alshmary ${ }^{2}$ \\ 'Department of Natural Product and Evidence Based Herbal Medicine, College of Pharmacy (Female Section) \\ Rafha Campus, Northern Border University, Kingdom of Saudi Arabia; heba_salem48@yahoo.com \\ ²Department of Clinical Pharmacy, College of Pharmacy (Female Section), Northern Border University, \\ Kingdom of Saudi Arabia; N300ooman@hotmail.com, 20bashair@gmail.com,muozn.man@gmail.com
}

\begin{abstract}
The present study aims towards investigating the risk of developing complications upon usage of different types of contact lens as well as the role played by different variables related to contact lens usage (replacement time, regular follow-up, etc). This is a retrospective cohort study. The total study sample $(n=143)$ were recruited from Rafha General Hospital, Northern Border Region, Saudi Arabia. All their data were collected and analyzed using chi square test. A P-Value of $<0.05$ was considered statistically significant. Reusable contact lens wearers were noted to have significantly more complications than disposable contact lens wearers $(P<0.05)$. The majority of the sample was reported to use contact lens for cosmetic (decorative) purpose than for therapeutic or optical indications (63\%). Regular follow-up was significantly associated with decrease incidence of contact lens complications $(P<0.01)$. Handling of reusable contact lenses must be done with care as complications are more likely to occur by using them than daily disposable contact lenses. Moreover, contact lens wearers must be advised about the importance of frequent replacement and regular follow-up as it showed significant decrease in complications. We can conclude from our finding that cosmetic usage of reusable contact lenses without proper handling and cleaning system is not advisable.
\end{abstract}

Keywords: Contact Lenses, Complications, Eye, Saudi Arabia

\section{Introduction}

Contact lenses are widely used in different populations for various reasons; cosmetic, therapeutic, as well as for optical indication. They were first introduced into the market for 22 years $^{1}$. And since then, remarkable improvements in the contact lens materials manufacture have been achieved, aiming towards producing a highly effective, comfortable and complication free contact lens. In general, there are two versions of contact lenses; daily disposable contact lenses (which are used for a single day and discarded upon its removal) and reusable contact lenses (which are cleaned and disinfected then reused again in the following day). Different types of contact lenses are available nowadays; rigid contact lenses (PMMA, RGP, Orthokeratology lenses), soft contact lenses (Hydrogel, Silicone hydrogel), and other contact lenses (Hybrid, Scleral, Hard/soft combination). Each of which has advantages and disadvantages. However, contact lenses, in general, have the leverage of being more comfortable, flexible, and convenient, besides offering more natural vision over conventional spectacles. Nevertheless, various reports have shown an increase rate of incidence of complications (allergies, giant papillary conjunctivitis, corneal abrasions, etc.) among users of contact lenses ${ }^{2-4}$, which necessitate the need to investigate different variables that might attribute to these complications. A recent focus in scientific research is directed towards investigating the

${ }^{*}$ Author for correspondence 
prevalence of eye infection among contact lens wearers in Saudi Arabia ${ }^{5,6}$. Thus, we conducted our study for the sake of answering the following research questions: the risk of developing complications among wearers of contact lens and significant association between different variables related to contact lens usage (replacement time, regular follow-up, etc.,) and developing complications, etc.

\section{Participants and Methods}

\subsection{Protocol}

This is a retrospective cohort study that investigates the risk of developing complications among wearer of contact lenses in Rafha district, Saudi Arabia. We used hospital records of Rafha General Hospital from 2012 to 2016 to collect the data required for our study. Patients who have used contact lens either daily disposable contact lenses or reusable contact lenses exclusively for therapeutic, cosmetic usage or optical indication were included in this study. We excluded patients who had a past history of eye diseases prior to the usage of contact lenses and those with incomplete data records. Any complication of contact lens usage was reported for each patient. The complications under investigation were categorized as follows: Giant Papillary Conjunctivitis, Keratitis, Corneal Abrasion, and Dry Eyes. Our analytic sample consists of 143 recruited patients that were classified according to type of contact lens used into daily disposable contact lens wearers $(n=25)$ and reusable contact lens wearers ( $n$ $=118$ ). All their data were collected and analyzed during the time period of June to September 2016. Nevertheless, we examined different variables related to contact lens wearing; demographic data, purpose of contact lens usage, replacement time, and regular follow up in developing complications. All variables were presented in Table 1.

\subsection{Statistical Analysis}

All data analysis was performed using IBM SPSS statistical software package (version 23 for windows). Pearson's chisquare test was calculated to investigate the association between wearing daily disposable contact lenses or reusable contact lenses and developing complications. We also tested the influence of different variables (Table 2) to determine their role in developing complications. An alpha level less than or equal to 0.05 was taken to indicate significant difference.

\section{Results}

The study sample included 143 individuals whose demographics presented in Table 1. The majority of the study sample declared using reusable contact lenses $(82.52 \%)$. The likelihood of using contact lens by females for cosmetic (decorative, beauty) purpose was significantly higher $(P<0.01)$ in comparison with therapeutic or optical indications. A greater number of reusable contact lens users (44.07\%) replace their contact lenses monthly. Furthermore, about third of the study sample followed-up ophthalmological clinics at regular intervals. Different complications; Giant Papillary Conjunctivitis, Keratitis, Corneal Abrasion, and Dry Eyes were presented in Table 2 against different variables under investigation. Complications were found to be significantly more in wearers of reusable contact lens rather than daily disposable contact lens $(P<0.05)$. Both frequent replacement and regular follow-up showed significant decrease in complications among contact lens wearers $(P<0.01)$. The probability of occurrence of different complications among contact lens wearers for cosmetic purpose was significantly increased $(P<0.01)$ (Table 2).

\section{Discussion}

This retrospective investigation provides an important update concerning complications of contact lens usage. Four different complications -listed in Table 2 were under investigation in the present study. A total of 51 complicated cases from the original sample number $(n=$ 143) was noted (Table 2). The results obtained from the present study highlight the following findings:

\subsection{Complications and Type of Contact Lens}

We found a significant decrease of complications among wearers of daily disposable contact lens than reusable contact lens $(P<0.05)$. In which, 49 complications where found among wearers of reusable contact lens while only 2 complications where found in daily disposable contact lens users. Since daily disposable contact lens are discarded on removal there are no concerns about lens storage or disinfection- as they are worn once during the day- which make them less susceptible to collect debris, microorganism or toxins beneath them that might cause 
Table 1. Demographic data and other characteristics of the study sample

\begin{tabular}{|c|c|c|c|c|}
\hline \multirow{3}{*}{$\begin{array}{l}\text { Demographic data and related } \\
\text { variable of contact lens usage }\end{array}$} & \multicolumn{4}{|c|}{ Types of Contact Lenses } \\
\hline & \multicolumn{2}{|c|}{ Daily disposable contact lens $(n=25)$} & \multicolumn{2}{|c|}{ Reusable contact lens $(n=118)$} \\
\hline & Number & Percentage & Number & Percentage \\
\hline \multicolumn{5}{|l|}{ Demographic data } \\
\hline Males & 3 & $12.00 \%$ & 7 & $5.93 \%$ \\
\hline Females & 22 & $88.00 \%$ & 111 & $94.07 \%^{\mathrm{a}}$ \\
\hline Age $(y)($ mean \pm SD) & \multicolumn{2}{|c|}{$(23.8 \pm 2.16)$} & \multicolumn{2}{|c|}{$(23.3 \pm 1.64)$} \\
\hline \multicolumn{5}{|l|}{ Purpose of contact lens usage } \\
\hline Cosmetic & 15 & $60.00 \%$ & 76 & $64.41 \%^{\mathrm{b}}$ \\
\hline Therapeutic & 6 & $24.00 \%$ & 14 & $11.86 \%$ \\
\hline Optical & 4 & $16.00 \%$ & 28 & $23.73 \%$ \\
\hline \multicolumn{5}{|l|}{ Replacement time } \\
\hline Daily & 25 & $100 \%$ & - & - \\
\hline Biweekly & - & - & 47 & $39.83 \%$ \\
\hline Monthly & - & - & 52 & $44.07 \%$ \\
\hline Annually & - & - & 19 & $16.10 \%$ \\
\hline Regular follow-up & 10 & $40 \%$ & 35 & $29.66 \%$ \\
\hline
\end{tabular}

${ }^{\mathrm{a}} P<0.05$.

${ }^{\text {b }} P<0.01$.

Table 2. Number of complications by type of contact lens used and related variables

\begin{tabular}{|c|c|c|c|c|c|}
\hline & \multicolumn{5}{|c|}{ Complications Related to Contact Lens Wear } \\
\hline $\begin{array}{l}\text { Contact Lens Type and } \\
\text { Related Variables }\end{array}$ & $\begin{array}{l}\text { Giant Papillary } \\
\text { Conjunctivitis }\end{array}$ & Keratitis & $\begin{array}{l}\text { Corneal } \\
\text { Abrasion }\end{array}$ & Dry Eyes & $\begin{array}{c}\text { Total } \\
\text { Complications }\end{array}$ \\
\hline \multicolumn{6}{|l|}{ Type of Contact Lens } \\
\hline Daily disposable contact lens & 0 & 1 & 1 & 0 & $2^{\mathrm{a}}$ \\
\hline Reusable contact lens & 3 & 14 & 17 & 15 & $49^{\mathrm{a}}$ \\
\hline Total & & & & & 51 \\
\hline \multicolumn{6}{|l|}{ Demographic data } \\
\hline Males & 0 & 2 & 0 & 1 & 3 \\
\hline Females & 3 & 13 & 18 & 14 & 48 \\
\hline \multicolumn{6}{|l|}{ Purpose of contact lens usage } \\
\hline Cosmetic & 2 & 3 & 11 & 11 & $27^{\mathrm{b}}$ \\
\hline Therapeutic & 0 & 7 & 3 & 3 & 13 \\
\hline Optical & 1 & 5 & 4 & 1 & 11 \\
\hline \multicolumn{6}{|l|}{ Replacement time } \\
\hline Daily & 0 & 1 & 1 & 0 & $2^{\mathrm{b}}$ \\
\hline Biweekly & 0 & 2 & 4 & 1 & 7 \\
\hline Monthly & 2 & 8 & 8 & 5 & 23 \\
\hline Annually & 1 & 4 & 5 & 9 & $19^{\mathrm{b}}$ \\
\hline Regular follow-up & 0 & 3 & 0 & 1 & $4^{b}$ \\
\hline
\end{tabular}

eye inflammation or infection than reusable contact lens which have to be cleaned and disinfected before wearing it again ${ }^{7}$.

\subsection{Contact Lens Usage and Risk of Complications}

The majority of recruited patients were reported to wear contact lens for cosmetic purpose. A significant increase in complications among them (27 complications) was noted, in comparison to 13 complication with therapeutic usage and 11 complications with optical indication $(P<0,01)$. This might be attributed to improper handling of contact lens among wearers who used them for cosmetic purposes. Any misuse of contact lens usage might cause 
unpleasant results. A previous case report of 70-yearsold gentleman who reuse contact lens, presented with reduced vision and corneal epithelial changes, turned out to have Acanthamoeba keratitis which is a sever condition that might cause visual loss 8 .

\subsection{Replacement Time and Contact Lens Complications}

Contact lens complications were found to be significantly higher in patients wearing reusable contact lenses with annual replacement $(P<0,01)$ which indicate that frequent replacement is a protective mean against contact lens complications as it decreases lens deposits. Concluded that frequent replacement for each patient on a weekly basis would be an ideal solution in preventing contact lens complications from the accumulation of deposits or abnormal reduction of lens's wetting characteristics?.

\subsection{Role of Regular Follow-Up}

A significant reduction of complications among contact lens wearers who performed regular follow-up was noted $(P<0,01)$, implying that continuous education about proper handling, cleaning, and disinfecting of contact lens during regular follow-up visits was an important element for prevention and early detection of contact lens complications. A previous study showed that receiving no information about contact lens care can increase the risk of having microbial keratitis by almost 20 -fold ${ }^{10}$.

\section{Comparison with Other Studies}

The main finding of the present study was that complications were statistically increased in wearers of reusable contact lens than daily disposable contact lens which is in agreement with previous reports ${ }^{11,12}$ which showed that complications of contact lenses are less likely to occur by using daily disposable contact lens than reusable contact lens.

\section{Conclusion}

Handling of reusable contact lenses must be done with care as complications are more likely to occur by using them than daily disposable contact lenses. Moreover, contact lens wearers must be advised about the importance of frequent replacement and regular follow-up as it showed significant decrease in complications. We can conclude from our finding that cosmetic usage of reusable contact lenses without proper handling and cleaning system is not advisable.

\section{Clinical Implications}

Weighting the advantages of contact lens usage over the disadvantages is important for each individual who intent to use them. Reusable contact lenses have the disadvantage of being more susceptible to collect debris and organisms beneath them, which increase the probability of complications. Therefore, health care practitioners should spend some time with patients to inform them about the importance of proper handling, cleaning, and disinfecting contact lenses. Additionally, patients must be encouraged for frequent replacement, and regular follow-up for early detection of any possible complication that might happen by using contact lens.

\section{Acknowledgment}

I would like to express my profound gratitude and deep regard to the staff of Rafha General Hospital for their support, advice, and insightful comments.

\section{Conflict of Interest}

The authors declare no conflict of interest.

\section{References}

1. Efron N, Morgan PB, Helland M, Itoi M, Jones D, Nichols JJ, van der Worp E, Woods CA. Daily disposable contact lens prescribing around the world. Contact Lens and Anterior Eye. 2010; 33(5):225-7.

2. Stapleton F, Naduvilath T, Keay L, Radford C, Dart JKG, Edwards K, et al. Risk factors for microbial keratitis in daily disposable contact lens wear. Investigative Ophthalmology and Visual Science. 2010; 51(13):1305.

3. Cho P, Boost MV. Daily disposable lenses: The better alternative. Contact Lens and Anterior Eye. 2013; 36(1):4-12.

4. Alasiri RA, Alqulayti WM, Neama SH, Alsulami IA, Bawazeer AM. Practice and knowledge of contact lens wear and care among female medical college students in kingdom of Saudi Arabia. International Journal of Biological and Medical Research. 2015; 6(4):5240-2.

5. Abdelkader A. Cosmetic soft contact lens associated ulcerative keratitis in Southern Saudi Arabia. Middle East African Journal of Ophthalmology. 2016; 21(3):232-5. 
6. Carla RA, Maria CM, Elisabetta C, Arturo P. Disposable contact lenses and bacterial adhesion. In vitro comparison between ionic/high-water-content and non-ionic/low-water-content lenses. Biomaterials. 1995; 16(9):685-90.

7. Marshall EC, Begley CG, Christina HD, Nguyen OD. Frequency of complications among wearers of disposable and conventional soft contact lenses. International Contact Lens Clinic. 1992; 19(3):55-60.

8. Nuwan N, Christopher DI. Acanthamoeba keratitis associated with misuse of daily disposable contact lenses. Contact Lens and Anterior Eye. 2006; 29(5):269-71.

9. Jones L. Disposable contact lenses: A review. Journal of the British Contact Lens Association. 1994; 17(2):43-9.
10. Sauer A, Bourcier T. French study group for contact lenses related microbial keratitis. microbial keratitis as a foreseeable complication of cosmetic contact lenses: A prospective study. Acta Ophthalmology. 2011; 89(5):439-42.

11. Chan KY, Cho P, Boost M. Microbial adherence to cosmetic contact lenses. Contact Lens and Anterior Eye. 2014; 37(4):267-72.

12. Hickson-Curran S, Spyridon M, Hunt C, Young G. The use of daily disposable lenses in problematic reusable contact lens wearers. Contact Lens and Anterior Eye. 2014; 37(4):285-91. 